\title{
Propolis and Its Implications in Dentistry: A Review
}

\author{
Sushmita Esh ${ }^{1}$, Avik Narayan Chatterjee ${ }^{2}$, Budhaditya De $^{3}$ \\ ${ }^{1}$ MDS (Conservative Dentistry and Endodontics), Dental Surgeon, Kamdahari, Purbapara, Garia, \\ Kolkata-700084 \\ ${ }^{2}$ MDS (Pediatric and Preventive Dentistry), Dental Surgeon, Kamdahari, Purbapara, Garia, Kolkata-700084 \\ ${ }^{3}$ MDS (Oral and Maxillofacial Pathology), Dental Surgeon, Kamdahari, Purbapara, Garia, Kolkata-700084
}

Corresponding Author: Avik Narayan Chatterjee

\begin{abstract}
Propolis is a resinous substance obtained from the beehives that has antioxidant, anti-bacterial, anti-viral, antifungal, and anti-inflammatory activity. Its diverse chemical content is responsible for many valuable properties. Multiple applications of propolis have been studied and described in detail for centuries. Propolis has been used for surgical wound healing, caries prevention, treatment of dentin hypersensitivity, treatment of aphthous ulcers and propolis as a storage medium for avulsed teeth, root canal irrigating solution, and mouthwash. This paper aims to indicate the uses of Propolis in various fields of dentistry.
\end{abstract}

Keywords: Dentistry, Propolis, Oral health

\section{INTRODUCTION}

The term propolis is derived from the Greek words 'pro' meaning for defense or in defense, and 'polis' meaning city; propolis thus stands for defense of the hive (city). ${ }^{1}$ Propolis, which is also known as bee glue, is a natural nontoxic resinous sticky substance produced by honeybees by mixing the secretions of their pharyngeal glands with the digested product of resins collected from leaves, flowers of plants, trees, and certain barks, and is mainly used as a sealant and sterilizer in honeybee nests. ${ }^{2,3}$ Propolis being a sticky substance, protects the hive from insects, rodents, robber bees, bacteria, fungi, larvae, maintains an ambient temperature, and also helps in repairing and covering the honeycombs. $^{4,5}$ The main propolis producing bees include the European honey bees (Apis mellifera) and Asian honey bees (Apis cerana, Apis florea, Apis andreniformis, and Apis dorsata). It also includes stingless bees, such as those of the genera Geniotrigona, Heterotrigona, Melipona, Tetragonula, and Trigona. ${ }^{6-8}$

Propolis is mainly composed of resin and balsams (50-70\%); essential oils, aromatic oils, and wax (30-50\%); pollen (5$10 \%)$; and other bioactive compounds such as amino acids, minerals, vitamins, phenolics, and flavonoids. ${ }^{9-11}$

Phenolics and flavonoids are responsible for the anti-oxidant properties exhibited by propolis. The extent of antioxidant activity of propolis is correlated with its total content of phenolics and flavonoids. $^{12}$

Propolis has anti-inflammatory properties. Propolis-derived caffeic acid phenethyl ester (CAPE), quercetin, and naringenin suppress the production of prostaglandins and leukotrienes which are the main mediators of inflammation. CAPE is most effective in modulating the arachidonic acid cascade. $^{13}$ Terpenoids extracted from propolis reduce the expression of inflammatory mediators, such as inducible nitric oxide synthase (iNOS), interleukin (IL)-1b, and IL-10. ${ }^{14}$ Propolis also suppresses the production of nuclear factor kappa-light-chain-enhancer of activated B cells (NF-kB). ${ }^{15,16}$ NF-kB plays an important role in many inflammationassociated human disorders including 
metabolic syndrome-related diseases such as cardiovascular disease, diabetes, and cancers. ${ }^{17-20}$

Propolis has anti-angiogenic and anti-proliferative properties. It is able to inhibit cancer cell metastasis by producing CAPE, which reduces the production of matrix metalloproteinases. ${ }^{21}$ CAPE has the ability to reduce the expression of various growth factors and transcription factors including NF-kB. ${ }^{22}$ CAPE exhibits the antiangiogenic properties by reducing vascular endothelial growth factor (VEGF) ${ }^{22}$ and downregulating the expression of multidrug resistance 1 (mdr1)gene; thus inhibiting the development of resistance of cancer cells to various chemotherapeutic agents. $^{23}$

Propolis exhibits antibacterial properties by its flavonoids and phenolics content; higher the content in the propolis variety, greater the antibacterial effect. It causes irreversible surface changes and reduces the surface negative charge resulting in pore formation in the membrane and extrusion of intra-cellular contents. ${ }^{24}$ Caffeic acid, rutin, chrysin, kaempferol, galangin, and quercetin derived from propolis exhibit antiviral activities against herpesvirus, adenovirus, coronavirus (including Sars Cov- 2), rotavirus, influenza virus, and HIV. ${ }^{25,26}$

\section{Use of Propolis in Dentistry}

Due to its antimicrobial, antioxidant, anti-inflammatory, and antiproliferative properties, propolis has immense potential in dentistry, oral health management, and medicine. ${ }^{27}$

Various genres of bacteria have been implicated in the development of caries. The most important are Streptococcus mutans and Lactobacillus sp. Other bacteria such as members of the mitis, anginosus, and salivarius groups of other Streptococcus sp., Enterococcus faecalis, Actinomyces sp., Rothia dentocariosa, Propionibacterium sp., Prevotella sp., Veillonella sp., Bifidobacterium sp., and Scardovia sp. have also been shown to contribute to the development and progression of caries. ${ }^{28-30}$ It has been found that propolis inhibits the growth of Streptococcus sobrinus, $S$. mutans, and Streptococcus cricetus. $^{31}$ Studies have shown that propolis-enriched drinking water resulted in a 50-60\% reduction in the incidence of dental caries in S. sobrinus infected rats. In addition, two propolis constituents, apigenin and ttfarnesol, significantly reduced smoothsurface caries in S. sobrinus-infected rats. ${ }^{32}$ It has been suggested that the protective effect of propolis is not only derived from phenolics and flavonoids; other fatty acids such as oleic, palmitic, linoleic, and stearic acid from propolis might also have beneficial properties. ${ }^{33}$ Propolis extractcontaining products have been effective in reducing and/or inhibiting the growth of S. mutans and other caries-causing bacteria in human clinical trials. A significant reduction in bacterial count has been observed among participants using propolis mouth rinse. ${ }^{34}$ Propolis and its constituents reduce the numbers of caries causing bacteria by directly inhibiting growth and/or inhibiting glucosyltransferase activity. In addition, propolis inhibits the synthesis of waterinsoluble glucan. ${ }^{31}$ Propolis also significantly reduces bacterial acid production and inhibits the activity of FATPase, an important enzyme associated with the acid tolerance of S. mutans. ${ }^{33}$

Due to its antimicrobial and antiinflammatory activities, propolis has been reported to reduce the incidence of plaque accumulation and gingivitis. Propoliscontaining mouth rinse reduces supragingival plaque and insoluble polysaccharide by $44.7 \%$ and $61.7 \%$, respectively, versus placebo where volunteers refrained from all oral hygiene and rinsed five times a day with $20 \%$ sucrose solution for 3 days. ${ }^{33}$ Chlorhexidine ( $\mathrm{CHX}$ ) has been used as an active ingredient in mouthwash because of its antimicrobial properties and efficacy in reducing dental plaque. Santiago et al. compared the effect of mouthwash containing $2.6 \% \quad(\mathrm{w} / \mathrm{v})$ propolis and a commercially available 
mouthwash containing $0.12 \%$ CHX on dental plaque accumulation. It was found that the propolis containing mouthwash was as effective as CHX mouthwash in reducing plaque accumulation over a trial period of 14 days. ${ }^{35}$ In patients with type 2 diabetes and chronic periodontitis, propolis has been shown to reduce hemoglobin A1c (HbA1c), fasting plasma glucose, and serum NV-(carboxymethyl)lysine $\quad$ (CML). ${ }^{36}$ Propolis also improves periodontal parameters, namely probing pocket depth (PPD) and clinical attachment level (CAL) (distance from the cement-toenamel junction to the base of the pocket). Additionally, topical application of propolis is beneficial in improving periodontal parameters, such as PPD, CAL, and reduce $\mathrm{P}$. gingivalis in the gingival crevicular fluid (GCF) in patients with periodontitis. ${ }^{37}$

Disinfection of the tooth cavity prior to restoration determines the success of the restorative treatment. Propolis has a disinfection efficacy in primary teeth similar to that of 2\% CHX and diode laser. Mohan $\mathrm{U}$ et al. investigated the efficacy of acidulated phosphate fluoride (APF) gel, propolis, laser diode, and $2 \% \mathrm{CHX}$ as disinfecting agents in 68 children with cavitated dentinal occlusal caries. They found that propolis reduced the total viable counts on blood agar, S. mutans counts on Mutans-Sanguis (MS) agar, and lactobacilli counts on Rogosa agar by $98 \%, 99 \%$, and $98 \%$, respectively. The results were comparable to those of diode laser and $2 \%$ $\mathrm{CHX}^{38}$ Recently propolis has been incorporated into nanocomposites and applied as restorative agents.

A major cause of endodontic diseases is bacteria and their metabolic products, enzymes, and toxins, which consequently induce inflammatory responses. Propolis has bactericidal activity comparable to that of common intracanal medicaments such as calcium hydroxide, CHX, MTAD (mixture of tetracycline, citric acid, and detergent), EDTA (ethylenediaminetetraacetic acid), camphorated paramonochlorophenol, and formocresol against various anaerobic, endodontitic-causing bacteria such as Prevotella nigrescens, F. nucleatum, Actinomyces israelii, Clostridium perfringens, and E. faecalis. Studies have shown that propolis exhibits better reduction in colony counts of E.fecalis than any other intra-canal medicaments. ${ }^{39,40}$

Propolis and its phenolic and flavonoid constituents with their antimicrobial, anti-inflammatory, and immunomodulatory properties are potential dental pulp capping materials. Ahangari et al. have shown that propolis-containing pulp capping agents stimulate higher levels of stem cell production and produce better quality of dentin in guinea pigs than calcium hydroxide. These agents produce tubular dentin, whereas $14 \%$ of the calcium hydroxide caps produce porous dentin. ${ }^{41}$ Propolis decreases the expression of Lipopolysaccharide(LPS)-induced

inflammatory mediators in pulp cells and osteoclasts. The inflammatory mediators that are suppressed include IL-1a, IL-6, IL12 (p70), IL-15, granulocyte colonystimulating factor (G-CSF), tumor necrosis factor-alpha (TNF-a), macrophage inflammatory protein 1 alpha (MIP-1a), monocyte chemoattractant protein-1 (MCP1), and interferon-inducible protein 10 (IP10). ${ }^{42}$ Parolia et al. compared Dycal, propolis, and mineral trioxide aggregate (MTA) as dental pulp capping materials in terms of inflammatory responses and dentine formation in patients aged 15-25 years and found that Propolis-and MTAtreated pulp exhibit less inflammation than that with Dycal. Propolis- and MTA treated pulp also show more dentine bridge formation than Dycal. ${ }^{43}$ Propolis induces wound healing by promoting epithelialization of the surgical wounds. Propolis also has anti-inflammatory and analgesic effects. ${ }^{44}$

Oral candidiasis is an opportunistic infection of the oral cavity caused by yeastlike fungi, most commonly Candida $s p$. Propolis extract has fungicidal activity against C. albicans, C. tropicalis, C. 
glabrata, and C. parapsilosis isolated from healthy subjects and patients with oral lesions. ${ }^{45}$ The effect of propolis is similar to nystatin or miconazole in treating denture stomatitis. ${ }^{46}$ The antifungal properties of propolis are due to its ability to disrupt the fungal cell wall and inhibit germ tube formation. Propolis prevents the adherence and colonization of fungi. ${ }^{47}$ Propolis has the ability to prevent biofilm formation, eradicate mature biofilms, and inhibit filamentation of Candida sp. Propolis also induces cell apoptosis in Candida $s p$. by affecting the metacaspase pathway and disrupting the Rascyclic AMP (cAMP)cAMP-dependent protein kinase (PKA) signaling pathway. ${ }^{48}$

The most prevalent virus affecting oral health is herpes simplex virus (HSV type I and II), type I being the most common. Propolis, owing to its constituents chrysin, galangin, kaempferol, and quercetin, have been reported to have antiviral properties against HSV in cell culture. The antiherpetic properties of propolis (and its phenolic constituents) are attributed to its ability to interfere with the virion envelope and consequently inhibit viral entry into cells. ${ }^{49}$

Propolis has antiangiogenic and antiproliferative properties. Propolis exhibits a time- and dose-dependent cytotoxic effect on human laryngeal epidermoid carcinoma. ${ }^{50}$ Some components of Propolis such as chrysin, caffeic acid, pcoumaric acid, and ferulic acid, induce apoptosis of human tongue squamous carcinoma cells (CAL-27). The polyphenols in propolis decrease collagen biosynthesis, prolidase activity, and proline concentration in CAL- 27 cells. ${ }^{51}$ Propolis has also been found to be effective in oral submucous fibrosis.

\section{Adverse Effects}

Propolis is a relatively safe product to be used in various aspects of dentistry. However, being a product obtained from bees, any allergic reaction from propolis or its constituents must be taken care of. Cases of contact dermatitis has been reported in literature. ${ }^{52}$

\section{CONCLUSION}

Propolis and its phenolic and flavonoid constituents have many therapeutic uses in dentistry, oral health, and medicine. Wide ranging therapeutic uses due to its antibacterial, antiviral, antifungal, anti-inflammatory, and anticancer properties have been demonstrated in various studies. However, there is a great need to standardize the content of phenolics and flavonoids in propolis to obtain the best therapeutic and medicinal benefits in dentistry and oral health.

Acknowledgement: None

\section{Conflict of Interest: None}

\section{Source of Funding: None}

\section{REFERENCES}

1. Ghisalberti E. Propolis: a review. Bee World 1979;60:59-84.

2. Coutinho A. Honeybee propolis extract in periodontal treatment: A clinical and microbiological study of propolis in periodontal treatment. Indian $\mathrm{J}$ Dent Res 2012;23:294.

3. Kamburoglu K, Ozen T. Analgesic effect of Anatolian propolis in mice. Agri 2011;23:47-50.

4. Dornelas CA, Fechine-Jamacaru FV, Albuquerque IL, Magalhaes HI, Souza AJ, Alves LA, et al. Chemoprevention with green propolis green propolis extracted in Llysine versus carcinogenesis promotion with L-lysine in N-Butyl-N-[4-hydroxybutyl] nitrosamine (BBN) induced rat bladder cancer. Acta Cir Bras 2012;2:185-92.

5. Wi,eckiewicz W, Miernik M, Wi, eckiewicz $\mathrm{M}$, Morawiec T.Does propolis help to maintain oral health? Evid Based Complement Alternat Med 2013;2013: 351062.

6. Seeley TD, Morse RA. The nest of the honey bee (Apis mellifera L.). Insectes Soc 1976;23:495-512. 
7. Simone-Finstrom M, Spivak M. Propolis and bee health: the natural history and significance. Apidologie 2010;41:295-311.

8. Popova M, Trusheva B, Bankova V. Propolis of stingless bees: a phytochemist's guide through the jungle of tropical biodiversity. Phytomedicine 2019;153098.

9. Kokelj F, Trevisan G. Contact dermatitis from propolis. Contact Dermatitis 1983;9. 518-518.

10. Monti M, Bertt E, Carminati G, Cusini M. Occupational and cosmetic dermatitis from propolis. Contact Dermatitis 1983;9. 163163.

11. Park YK, Alencar SM, Aguiar CL. Botanical origin and chemical composition of Brazilian propolis. J Agric Food Chem 2002;50:2502-6.

12. Kumazawa S, Ueda R, Hamasaka T, Fukumoto S, Fujimoto T, Nakayama T. Antioxidant prenylated flavonoids from propolis collected in Okinawa, Japan. J Agric Food Chem 2007;55:7722-5.

13. Mirzoeva OK, Calder PC. The effect of propolis and its components on eicosanoid production during the inflammatory response. Prostaglandins Leukot Essent Fatty Acids 1996;55:441-9.

14. Zhang W, Cai Y, Chen X, Ji T, Sun L. Optimized extraction based on the terpenoids of Heterotrigona itama propolis and their antioxidative and antiinflammatory activities. J Food Biochem 2020;44:e13296.

15. Wang K, Ping S, Huang S, Hu L, Xuan H, Zhang $\mathrm{C}$, et al. Molecular mechanism underlying the in vitro anti-inflammatory effects of a flavonoid-rich ethanol extract from Chinese propolis (poplar type). Evidence-Based Complement Altern Med 2013;2013:127672.

16. Corr $\wedge$ ea FRS, Schanuel FS, Moura-Nunes N, Monte-Alto-Costa A, Daleprane JB. Brazilian red propolis improves cutaneous wound healing suppressing inflammationassociated transcription factor NFkB. Biomed Pharmacother 2017;86:162-71.

17. Christman JW, Blackwell TS, Juurlink BHJ. Redox regulation of nuclear factor kappa B: therapeutic potential for attenuating inflammatory responses. Brain Pathol 2000;10:153-62.

18. Burke JR. Targeting IkB kinase for the treatment of inflammatory and other disorders. Curr Opin Drug Discov Dev 2003;6:720-8.

19. Wright JG, Christman JW. The role of nuclear factor Kappa B in the pathogenesis of pulmonary diseases: implications for therapy. Am J Respir Med 2003;2:211-9.

20. Gonzalez-Ramos R, Defere S, Devoto L. Nuclear factor-kappaB: a main regulator of inflammation and cell survival in endometriosis pathophysiology. Fertil Steril 2012;98:520-8.

21. Hwang HJ, Park HJ, Chung HJ, Min HY, Park EJ, Hong JY, et al. Inhibitory effects of caffeic acid phenethyl ester on cancer cell metastasis mediated by the down-regulation of matrix metalloproteinase expression in human HT1080 fibrosarcoma cells. J Nutr Biochem 2006;17:356-62.

22. Wu J, Omene C, Karkoszka J, Bosland M, Eckard J, Klein CB, et al. Caffeic acid phenethyl ester (CAPE), derived from a honeybee product propolis, exhibits a diversity of anti-tumor effects in pre-clinical models of human breast cancer. Canc Lett 2011;308:43-53.

23. Chu F, Chou PM, Zheng X, Mirkin BL, Rebbaa A. Control of multidrug resistance gene mdr1 and cancer resistance to chemotherapy by the longevity gene sirt1. Canc Res 2005;65:10183-7.

24. Borges A, Ferreira C, Saavedra MJ, Sim oes M. Antibacterial activity and mode of action of ferulic and gallic acids against pathogenic bacteria. Microb Drug Resist 2013;19:256-65.

25. Gekker G, Hu S, Spivak M, Lokensgard JR, Peterson PK. Anti-HIV-1 activity of propolis in CD4p lymphocyte and microglial cell cultures. J Ethnopharmacol 2005;102:158-63.

26. Refaat H, Mady FM, Sarhan HA, Rateb HS, Alaaeldin E. Optimization and evaluation of propolis liposomes as a promising therapeutic approach for COVID-19. Int J Pharm 2020;592:120028.

27. Khurshid Z, Naseem M, Zafar MS, Najeeb S, Zohaib S. Propolis: a natural biomaterial for dental and oral healthcare. J Dent Res Dent Clin Dent Prospects 2017;11:265-74.

28. Aas JA, Griffen AL, Dardis SR, Lee AM, Olsen I, Dewhirst FE, et al. Bacteria of dental caries in primary and permanent teeth in children and young adults. J Clin Microbiol 2008;46:1407-17. 
29. Munson MA, Banerjee A, Watson TF, Wade WG. Molecular analysis of the microflora associated with dental caries. J Clin Microbiol 2004;42:3023-9.

30. Ling Z, Kong J, Jia P, Wei C,Wang Y, Pan $\mathrm{Z}$, et al. Analysis of oral microbiota in children with dental caries by PCR-DGGE and barcoded pyrosequencing. Microb Ecol 2010;60:677-90.

31. Ikeno K, Ikeno T, Miyazawa C. Effects of propolis on dental caries in rats. Caries Res 1991;25:347-51.

32. Koo H, Rosalen PL, Cury JA, Park YK, Bowen WH. Effects of compounds found in propolis on Streptococcus mutans growth and on glucosyltransferase activity. Antimicrob Agents Chemother 2002;46:1302-9.

33. Duarte S, Rosalen PL, Hayacibara MF, Cury JA, Bowen WH, Marquis RE, et al. The influence of a novel propolis on mutans streptococci biofilms and caries development in rats. Arch Oral Biol 2006;51:15-22.

34. Duailibe SADC, Gonçalves AG, Ahid FJM. Effect of a propolis extract on Streptococcus mutans counts in vivo. J Appl Oral Sci 2007;15:420-3.

35. Santiago KB, Piana GM, Conti BJ, Cardoso $\mathrm{E}$ de $\mathrm{O}$, Andrade BFMT, Zanutto MR, et al. Microbiological control and antibacterial action of a propolis containing mouthwash and control of dental plaque in humans. Nat Prod Res 2018;32:1441-5.

36. El-Sharkawy HM, Anees MM, Van Dyke TE. Propolis improves periodontal status and glycemic control in patients with type 2 diabetes mellitus and chronic periodontitis: a randomized clinical trial. J Periodontol 2016;87: 1418-26.

37. Nakao R, Senpuku H, Ohnishi M, Takai H, Ogata Y. Effect of topical administration of propolis in chronic periodontitis. Odontology 2020;108:704-14.

38. Uday Mohan PVM, Uloopi KS, Vinay C, Rao RC. In vivo comparison of cavity disinfection efficacy with APF gel, Propolis, Diode Laser, and $2 \%$ chlorhexidine in primary teeth. Contemp Clin Dent 2016;7:45-50.

39. de Andrade Ferreira FB, Torres SA, da Silva Rosa OP, Ferreira CM, Garcia RB, Marcucci MC, et al. Antimicrobial effect of propolis and other substances against selected endodontic pathogens. Oral
Surgery. Oral Med Oral Pathol Oral Radiol Endodontology 2007;104:709-16.

40. Mattigatti S, Jain D, Ratnakar P, Moturi S, Varma S, Rairam S. Antimicrobial effect of conventional root canal medicaments vs propolis against Enterococcus faecalis, Staphylococcus aureus and Candida albicans. J Contemp Dent Pract 2012;13: 305-9.

41. Ahangari Z, Naseri M, Jalili M, Mansouri Y, Mashhadiabbas F, Torkaman A. Effect of propolis on dentin regeneration and the potential role of dental pulp stem cell in Guinea pigs. Cell J 2012;13:223-8.

42. Neiva KG, Catalfamo DL, Holliday S, Wallet SM, Pileggi R. Propolis decreases lipopolysaccharide-induced inflammatory mediators in pulp cells and osteoclasts. Dent Traumatol 2014;30:362-7.

43. Parolia A, Kundabala M, Rao NN, Acharya $\mathrm{SR}$, Agrawal $\mathrm{P}$, Mohan $\mathrm{M}$, et al. A comparative histological analysis of human pulp following direct pulp capping with Propolis, mineral trioxide aggregate and Dycal. Aust Dent J 2010;55:59-64.

44. Magro-Filho O, de Carvalho AC. Topical effect of propolis in the repair of sulcoplasties by the modified Kazanjian technique. Cytological and clinical evaluation. J Nihon Univ Sch Dent 1994;36: 102-11.

45. Azevedo RVP, Komesu MC, Candido RC, Salvetti C, Rezende FHC. Candida sp in the oral cavity with and without lesions: maximal inhibitory dilution of propolis and periogard. Rev Microbiol 1999;30:335-41.

46. Capistrano HM, De Assis EM, Leal RM, Alvarez-Leite ME, Brener S, Bastos EMAF. Brazilian green propolis compared to miconazole gel in the treatment of Candida associated denture stomatitis. EvidenceBased Complement Altern Med 2013; 947980.

47. Mello AM, Gomes RT, Lara SR, Silva LG, Alves B, Cortes ME, et al. The effect of Brazilian propolis on the germ tube formation andd cell wall of Candida albicans. Pharmacologyonline 2006;3:3528.

48. De Castro PA, Bom VLP, Brown NA, Almeida RSC de, Ramalho LNZ, Savoldi $\mathrm{M}$, et al. Identification of the cell targets important for propolis-induced cell death in Candida albicans. Fungal Genet Biol 2013;60:74-86. 
49. Schnitzler P, Neuner A, Nolkemper S, Zundel C, Nowack $\mathrm{H}$, Sensch $\mathrm{KH}$, et al. Antiviral activity and mode of action of propolis extracts and selected compounds. Phyther Res 2010;24:632.

50. Búfalo MC, Candeias JMG, Sforcin JM. In vitro cytotoxic effect of Brazilian green propolis on human laryngeal epidermoid carcinoma (HEp-2) cells. Evidence-Based Complement Altern Med 2009;6:483-7.

51. Celinska-Janowicz K, Zarba I, Lazarek U, Teul J, Tomczyk M, Pałka J, et al. Constituents of propolis: chrysin, caffeic acid, p-coumaric acid, and ferulic acid induce PRODH/POX-dependent apoptosis in human tongue squamous cell carcinoma cell (CAL-27). Front Pharmacol 2018; 9:336.

52. De Groot AC. Propolis: a review of properties, applications, chemical composition, contact allergy, and other adverse effects. Dermatitis 2013;24:263-82.

How to cite this article: Sushmita Esh, Chatterjee AN, Budhaditya De. Propolis and its implications in dentistry: a review. International Journal of Research and Review. 2021; 8(12): 311-317. DOI: https://doi.org/10.52403/ijrr. 20211238 